\title{
Clinical relevance and treatment of nonautoimmune anemia in chronic lymphocytic leukemia
}

This article was published in the following Dove Press journal:

Cancer Management and Research

3I May 20I I

Number of times this article has been viewed

\author{
Stefano Molica' \\ Rosanna Mirabelli' \\ Matteo Molica' \\ Luciano Levato' \\ Francesca R Mauro ${ }^{2}$ \\ Robin Foà ${ }^{2}$ \\ 'Department of Hematology and \\ Oncology, Azienda Ospedaliera \\ Pugliese-Ciaccio, Catanzaro; \\ ${ }^{2}$ Department of Cellular \\ Biotechnologies and Hematology, \\ Division of Hematology, Sapienza \\ University, Rome, Italy
}

Correspondence: Stefano Molica Department Hematology and Oncology, Azienda Ospedaliera Pugliese-Ciaccio, Viale Pio X, Catanzaro 88100, Italy $\mathrm{Tel}+390961883001$

Fax +390961888221

Email smolica@libero.it

\begin{abstract}
Anemia has an unfavorable impact on quality of life in chronic lymphocytic leukemia (CLL), increases the likelihood of receiving blood transfusions, and eventually has a negative impact on overall survival. Although discrepancies in perception of health-related quality of life between doctors and patients lead to the undertreatment of anemia, CLL patients undergoing chemotherapy who have a hemoglobin level $<10 \mathrm{~g} / \mathrm{dL}$ should be considered for treatment with erythropoiesis-stimulating agents. For hemoglobin values of 10-12 g/dL, the role of performance status and comorbidities should not be underestimated. In this setting, the evaluation of physical fitness using the Cumulative Illness Rating Scale should help physicians to identify those patients with hemoglobin levels of $10-12 \mathrm{~g} / \mathrm{dL}$ who are suitable for therapy with erythropoiesis-stimulating agents. Finally, the increasing use of aggressive approaches to therapy should encourage physicians towards appropriate management of chemotherapyinduced anemia in CLL patients.
\end{abstract}

Keywords: anemia, chronic lymphocytic leukemia, erythropoietin

\section{Introduction}

Chronic lymphocytic leukemia (CLL) is the most common form of adult leukemia in Western countries, with an annual incidence of 2-4.5 per 100,000 new cases. ${ }^{1}$ The disease is twice as common in men as it is in women, and affects mostly the elderly, with the median age at diagnosis being 73 years. After decades of remaining static, the management of LLC is now rapidly evolving. The introduction of purine analogs, followed by monoclonal antibodies, has revitalized clinical research in CLL. Furthermore, autologous hematopoietic stem cell transplantation is a feasible option, with low treatment-related mortality, although there are questions relating to optimal timing of the procedure, the conditioning regimen, and late effects. ${ }^{2-7}$ A series of biomarkers including CD38, immunoglobulin, mutational status, zeta chain-associated protein kinase 70, and cytogenetics, as well as TP53 mutations, have improved the prognostic evaluation of patients with CLL and helped to identify risk-adapted treatment programs. ${ }^{8,9}$

Despite these achievements, the results of recent clinical trials have shown a limited impact on overall survival. Therefore, in this context, it is important to ensure an adequate quality of life for patients. ${ }^{10}$ The changes in quality of life for patients with CLL are closely related to the degree of anemia, although duration of disease, type and intensity of chemotherapy, and intercurrent infection have an important role. ${ }^{11}$ This review deals with the pathogenesis, clinical significance, and treatment of nonautoimmune hemolytic anemia in patients with CLL. We also attempt to provide useful practical support for day-by-day clinical practice. 


\section{Incidence of anemia}

Although an increasing number of patients with CLL are now diagnosed at an early stage of disease, the results of a recent monoinstitutional study, which analyzed changes in the pattern of disease presentation over the last 30 years, indicate that the incidence of anemia ranges between $5 \%-6 \% .^{12}$ Anemia in CLL may also be secondary to chemotherapy or chemoimmunotherapy, and combinations of fludarabine, cyclophosphamide, and rituximab induce anemia, with a frequency ranging between $5.4 \%$ and $24 \%$ in relation to use in untreated or previously treated patients. ${ }^{13,14}$ Finally, CLL patients may develop autoimmune hemolytic anemia, with a rate ranging between $2.9 \%$ for stable Binet stage A and $10.5 \%$ for Binet stages B and C. ${ }^{15}$

\section{Pathogenesis of nonautoimmune hemolytic anemia}

The pathogenesis of nonautoimmune hemolytic anemia in CLL is a relatively unaddressed issue. Recently, Tsopra et a ${ }^{16}$ in a study involving 56 CLL patients established that bone marrow infiltration was not the only factor responsible for anemia. In addition, CD34-positive cells were able to generate erythroid precursors, while circulating levels of erythropoietin were within the normal range. In the same patient cohort, it was also found that serum levels of tumor necrosis factor-alpha (TNF- $\alpha$ ) were higher in patients with anemia, and the addition of TNF- $\alpha$ inhibited erythroid growth in the early stages of erythropoiesis. ${ }^{16}$ These results led to the conclusion that CLL-related anemia is not an expression of an intrinsic defect of erythroid precursors, but the result of direct suppression of erythropoiesis by TNF- $\alpha$. Figure 1 shows the pathway for differentiation of erythroid progenitors into mature red blood cells. The progenitors express receptors for the inflammatory cytokines necessary for normal differentiation into red blood cells, but, in conditions of absolute or relative deficiency of erythropoietin, these cytokines facilitate erythrocyte death. This model is designed to explain the pathogenesis of anemia in patients with solid tumors, and may also be used to elucidate mechanisms underlying the development of anemia in CLL. ${ }^{17}$

\section{Consequences of anemia}

Anemia plays an important role in promoting the angiogenic processes involved in the progression of CLL, whereby altered tissue oxygenation secondary to anemia leads to exaggerated production of angiogenic cytokines (vascular endothelial growth factor, basic fibroblast growth factor) by either leukemic or bone marrow microenvironment cells. ${ }^{18}$
Different studies have demonstrated an increase of bone marrow microvessels, as well as higher circulating levels of vascular endothelial growth factor, correlate with biological features of poor prognosis ${ }^{19}$ (Figure 2). From a clinical standpoint, anemia in patients with CLL has an unfavorable impact on the quality of life, increases the likelihood of receiving blood transfusions, and eventually has a negative impact on overall survival. ${ }^{20,21}$

The changes in parameters related to quality of life can be underestimated in patients with CLL. ${ }^{10}$ The results of the prospective LFR Chronic Lymphocytic Leukaemia Trial 4 highlight the role of anemia in determining clinically meaningful changes in quality of life, especially when associated with a higher tumor burden and progressive disease. ${ }^{11}$

Anemia is an independent risk factor related to higher incidence of complications from chemotherapy. Most antineoplastic agents bind to red blood cells, so the increased concentration of free drug in the bloodstream strengthens the risk of toxicity in anemic CLL patients. ${ }^{20}$ Finally, the importance of anemia as a prognostic factor is supported by the negative correlation between low hemoglobin levels and reduced survival. Hemoglobin concentrations $<10-11 \mathrm{~g} / \mathrm{dL}$ define a subgroup of patients at high risk both in the Rai (ie, stage III) and Binet (ie, stage C) classifications. ${ }^{22,23}$ Importantly, patients with advanced (ie, Binet stage C) disease due to an autoimmune mechanism had significantly better survival than those in an advanced stage related to massive bone marrow infiltration (median survival 7.4 years versus 3.7 years, $P=0.02) .{ }^{24}$ These results emphasize the importance of determining the origin of anemia and/or thrombocytopenia in patients with CLL, for both treatment and prognostic purposes.

\section{Use of erythropoietin in CLL}

Although most clinical studies of erythropoiesis-stimulating agents have included patients with epithelial cancers, there is clear evidence, supported by the results of meta-analysis, that their efficacy is similar in hematologic malignancies. ${ }^{25}$ The major advantage of erythropoiesis-stimulating agents over blood transfusions has been the maintenance of consistent hemoglobin levels, as well as the reduction in risk of transfusion-related immunomodulation. ${ }^{25}$

Among the different erythropoiesis-stimulating agents, epoietin has been the most widely used in the treatment of patients with CLL $^{26-29}$ (see Table 1). In a prospective, double-blind trial, 221 anemic CLL patients were randomized to receive epoetin alfa $150 \mathrm{U} / \mathrm{kg}$ or placebo three 


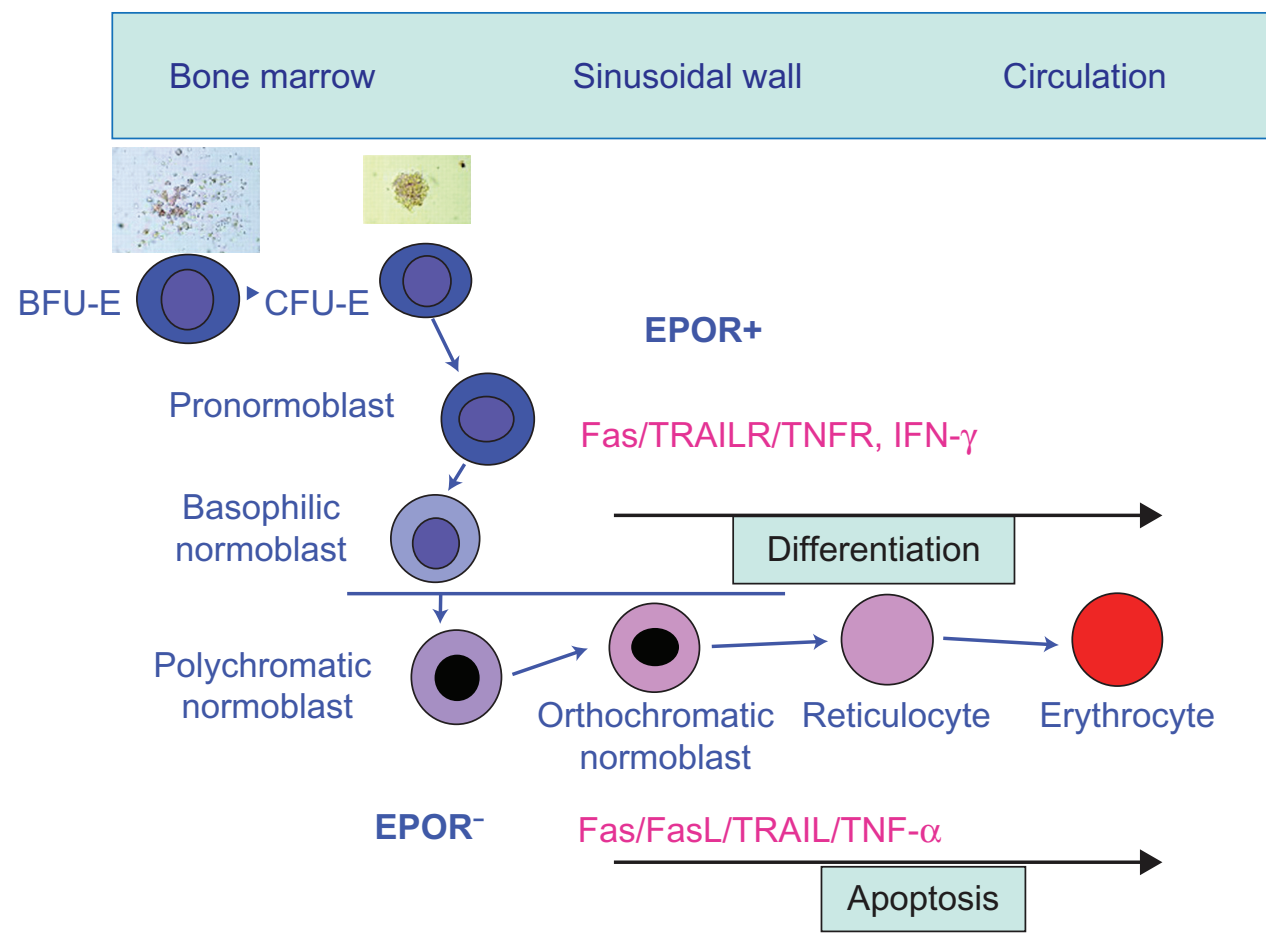

Figure I Differentiation of erythroid progenitors to mature red blood cells. As shown, the progenitors express receptors for the inflammatory cytokines necessary for normal differentiation into red blood cells, but, in conditions of absolute or relative deficiency of erythropoietin, these cytokines facilitate erythrocyte death.

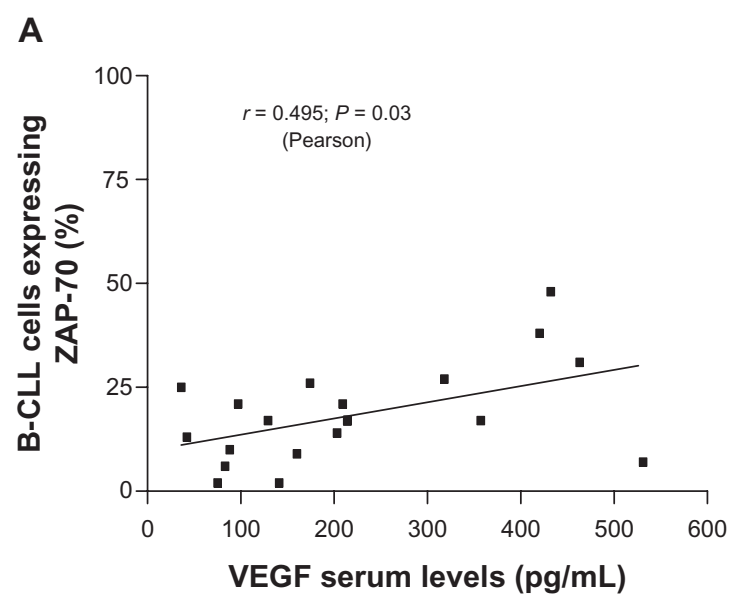

B

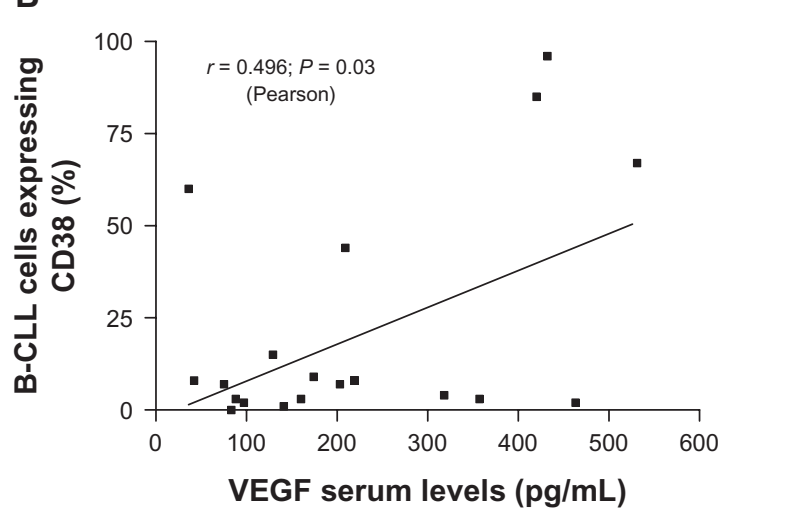

C

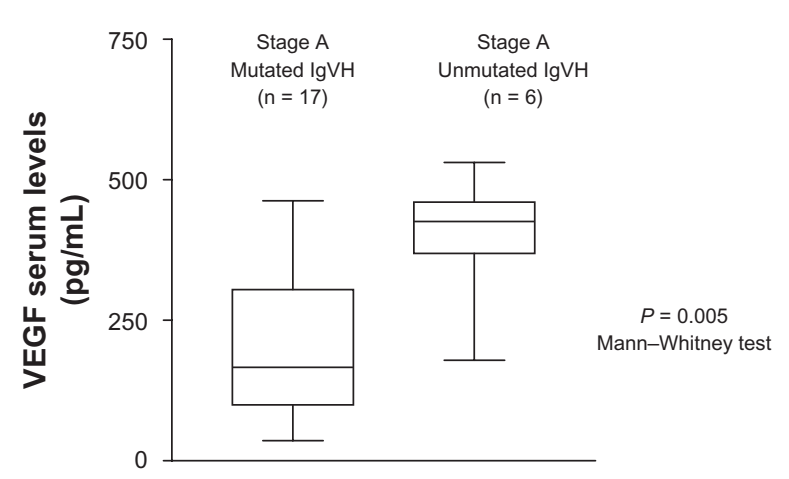

Figure 2 Correlation between vascular endothelial growth factor and zeta chain-associated protein kinase 70 A), CD38-expression B) and mutational status IgVH C). 
Table I Studies of erythropoietin in chronic lymphocytic leukemia

\begin{tabular}{llllll}
\hline Author & $\begin{array}{l}\text { Patients } \\
(\mathbf{n})\end{array}$ & Erythropoietin & Type of study & $\begin{array}{l}\text { Response } \\
\text { rate (\%) }\end{array}$ & $\begin{array}{l}\text { Improvement in } \\
\text { quality of life }\end{array}$ \\
\hline Rose et al $^{26}$ & 221 & EPO- $\alpha$ & $\begin{array}{l}\text { Phase II } \\
\text { (placebo-controlled) }\end{array}$ & $50 \%$ & Yes \\
Siakantaris et al ${ }^{27}$ & 22 & EPO- $\alpha$ & Phase II (dose- escalation) & $88 \%$ & No \\
Österborg et al $^{28}$ & 126 & EPO- $\beta$ & Phase III (placebo-controlled) & $63 \%$ & Yes \\
Pangalis et al $^{29}$ & 25 & EPO- $\alpha$ & Phase II (pilot) & $80 \%$ & Not available \\
\hline
\end{tabular}

Abbreviation: EPO, erythropoietin.

times weekly. Treatment with epoetin alfa led to an increase in hematocrit values by $>6 \%$ in $50 \%$ of treated patients. This study also showed that the increased hemoglobin levels translated into an improvement in quality of life. ${ }^{26}$ In a doseescalation trial, epoetin alfa was administered at an initial dose of $150 \mathrm{U} / \mathrm{kg}$ three times per week. In nonresponders, the dose was gradually increased to a maximum of $300 \mathrm{U} /$ $\mathrm{kg}$. A complete response (final hematocrit $>38 \%$ ) was observed in $55 \%$ of patients, and a partial response (increase in hematocrit $\geq 6 \%$ ) in $33 \%$ of patients. In the same study, a role of maintenance therapy using epoetin alfa $150 \mathrm{U} / \mathrm{kg}$ per week on duration of response was demonstrated. ${ }^{27}$

In a placebo-controlled trial that included patients with multiple myeloma and non-Hodgkin's lymphoma, Osterborg et $\mathrm{al}^{28}$ treated 126 CLL patients with transfusiondependent anemia and low levels of erythropoietin. In this study, the primary endpoint of which was the transfusionfree interval between the fifth and sixteenth week after initiation of therapy with epoetin beta, the risk of needing a blood transfusion was reduced by $40 \%$ in patients treated with epoetin beta compared with controls.

Pangalis et $\mathrm{al}^{29}$ assessed the efficacy of recombinant erythropoietin in 25 patients with CLL in Rai stage III, with the idea that treatment of anemia could translate into a delay in the start of chemotherapy and/or into possible advantage for overall survival. Treatment with recombinant erythropoietin produced a complete response (increase in hematocrit value $>38 \%$ ) in 18 of 25 patients and a partial response (increase greater than $6 \%$ of hematocrit values but, overall, $<38 \%$ ) in two patients. In addition, 19 patients obtained a downstaging of disease, with a change to Rai stage 0 in six patients and to Rai stage I-II in 13 patients. After a median follow-up of 32 months, only four patients needed antileukemic treatment, and survival rates projected at three years were $84 \%$. Although the results reported by Pangalis et $\mathrm{al}^{29}$ appear interesting, further clinical trials are needed to determine whether recombinant erythropoietin has any impact on the outcome of disease and whether this effect translates into a survival benefit.

\section{CLL cells and erythropoietin receptors}

There has been intense debate in the scientific community recently concerning the possibility that recombinant erythropoietin may have a role in the mechanism of tumor progression. On the other hand, the results of two prospective, placebo-controlled studies showed that patients with head and neck and breast cancer treated with erythropoietin had a worse clinical outcome compared with controls. ${ }^{30,31}$ Erythropoietin is currently used to treat chemotherapy-induced anemia in patients with lymphoproliferative disorders. However, information on the expression of erythropoietin receptors by tumor cells is limited. Kokhaei et a ${ }^{32}$ recently reported the results of a group of CLL patients analyzed for either the expression of erythropoietin receptors or the effects on leukemic cells induced by different erythropoiesis-stimulating agents in vitro. Despite the presence of erythropoietin receptor mRNA, the corresponding membrane protein was never identified, and it was not possible to document the phenomena of activation or cell proliferation after stimulation with CD40L-transfected fibroblasts. These results suggest that erythropoiesis-stimulating agents can be used with reasonable safety in patients with CLL and anemia related to chemotherapy. However, physicians should refer to current guidelines, and consider the benefits and risks associated with use of erythropoiesis-stimulating agents. From a clinical standpoint, a recent meta-analysis including 12 randomized studies, including a total of 2297 patients with solid tumors or nonmyeloid hematological malignancies, demonstrated that epoetin beta does not have any impact on survival or tumor progression. ${ }^{33}$

\section{Recommendations for use of erythropoietic growth factors}

A panel of international experts was convened in June 1999 in Barcelona to make recommendations for the optimal use of erythropoiesis-stimulating agents in CLL and multiple myeloma. ${ }^{34}$ Many observations made at this consensus conference are part of the recently updated American Society 
of Hematology/American Society of Clinical Oncology guidelines, ${ }^{25,35,36}$ the important points of which are summarized below.

Treatment of CLL-related anemia should be directed to the deferral or reduction of transfusion requirements and improvement in quality of life. The use of antileukemic treatment and evaluation of its effectiveness should precede the use of erythropoiesis-stimulating agents. After 2-3 cycles of chemotherapy or chemoimmunotherapy, in the absence of a hemoglobin increase, treatment with erythropoiesis-stimulating agents should be considered in agreement with American Society of Hematology/ American Society of Clinical Oncology guidelines. ${ }^{25,35,36} \mathrm{~A}$ systematic review of literature based on 40 studies including 21,376 patients showed that the clinical benefits and risks associated with the use of erythropoiesis-stimulating agents do not differ according to the use of epoetin or darbepoetin. ${ }^{37}$

Treatment with erythropoiesis-stimulating agents is generally recommended for all patients with CLL and hemoglobin $<10 \mathrm{~g} / \mathrm{dL}$. For hemoglobin values in the $10-12 \mathrm{~g} / \mathrm{dL}$ range, the role of performance status and comorbidities should not be underestimated. For instance, a Cumulative Illness Rating Scale $>6$ in patients older than 65 years should prompt physicians to consider treatment with erythropoiesisstimulating agents. ${ }^{13}$ Also, the presence of cardiac comorbidity in the elderly should be considered an indication for starting erythropoiesis-stimulating agents in patients with hemoglobin levels $<12 \mathrm{~g} / \mathrm{dL}$. Recombinant erythropoietin protects cardiomyocytes from hypoxic damage leading to apoptosis, and a Phase III clinical trial has recently been initiated to clarify the effects of recombinant erythropoietin on the outcome in patients with chronic heart failure. ${ }^{38}$ The aim of treatment with erythropoiesis-stimulating agents is to achieve a hemoglobin level of $12 \mathrm{~g} / \mathrm{dL}$, using an initial dose of 40,000 U of epoetin once a week. This dose and administration schedule have proved to be as effective as $10,000 \mathrm{U}$ three times a week. ${ }^{25,35,36}$

Lack of response to therapy is defined as an increase in hemoglobin of $<1 \mathrm{~g} / \mathrm{dL}$ after at least four weeks of treatment with erythropoiesis-stimulating agents. If the patient is receiving 10,000 IU of epoetin three times a week, the dose may be doubled. In the event of no response to the weekly dose of 40,000 IU, a dose increase to 60,000 IU once a week is recommended. A lack of response after an increased dose should prompt the clinician to consider the patient refractory to erythropoiesis-stimulating agents and to consider conditions responsible for failure. ${ }^{25,35,36}$ For example, a diagnosis of autoimmune hemolytic anemia should not be ruled out. Therefore, a diagnosis of autoimmune hemolytic anemia, expecially in patients who are receiving fludarabine as a single agent, should be ruled out. ${ }^{15}$ The subgroup of patients who reach a hemoglobin level $>12 \mathrm{~g} / \mathrm{dL}$ but $<14 \mathrm{~g} / \mathrm{dL}$ may be considered for maintenance erythropoietin, administered at two-weekly intervals.

Finally, CLL patients treated with lenalidomide are candidates to receive erythropoiesis-stimulating agents, and represent a subgroup at high risk of thromboembolic episodes. ${ }^{39}$ Although there are no defined risk factors for thromboembolism in patients with CLL, clinicians should exercise caution with concomitant use of erythropoietic growth factors and lenalidomide.

\section{Conclusion}

Anemia in CLL is associated with decreased survival, reduced quality of life, increased risk of chemotherapyrelated toxicity, and increased use of blood transfusions. ${ }^{40}$ Erythropoiesis-stimulating agents have an important advantage over blood transfusions in the treatment of CLLrelated anemia. ${ }^{25,35,36}$ However, they should be avoided in patients with CLL not receiving concurrent chemotherapy. For patients undergoing chemotherapy who have a hemoglobin level $<10 \mathrm{~g} / \mathrm{dL}$, clinicians should discuss potential risks (eg, thromboembolism, shorter survival) and benefits (eg, decreased transfusions) of erythropoiesis-stimulating agents, and balance these with the potential risks (eg, serious infections, immune-mediated adverse reactions) and benefits (eg, rapid hemoglobin improvement) of red blood cell transfusion. ${ }^{25,35,36}$ Individual preferences for assumed risk should contribute to the shared decision-making in the management of chemotherapy-induced anemia. If used, erythropoiesis-stimulating agents should be administered at the lowest dose possible and should increase hemoglobin to the lowest concentration possible to avoid transfusions. Erythropoiesis-stimulating agents should be discontinued after 6-8 weeks in nonresponders. Caution should be exercised when using erythropoiesis-stimulating agents with antileukemic agents (ie, lenalidomide) because of the increased risk of thromboembolic complications.

\section{Disclosure}

The authors report no conflicts of interest in this work.

\section{References}

1. Jemal A, Siegel R, Ward E, Hao Y, Xu J, Thun MJ. Cancer statistics, 2009. CA Cancer J Clin. 2009;59:225-249. 
2. Catovsky D, Richards S, Matutes E, et al. Assessment of fludarabine plus cyclophosphamide for patients with chronic lymphocytic leukaemia (the LRF CLL4 trial): A randomized controlled trial. Lancet. 2007;370:230-239.

3. Hillmen P, Skotnicki AB, Robak T, et al. Alemtuzumab compared with chlorambucil as first-line therapy for chronic lymphocytic leukemia. J Clin Oncol. 2007;25:5616-5623.

4. Wierda WG, Kipps TJ, Mayer J, et al. Ofatumumab as single agent CD20 immunotherapy in fludarabine-refractory chronic lymphocytic leukemia. J Clin Oncol. 2010;28:1749-1755.

5. Knauf WU, Lissichkov T, Aldaoud A, et al. Phase III randomized study of bendamustine compared with chlorambucil in previously untreated patients with chronic lymphocytic leukemia. J Clin Oncol. 2009;27: 4378-4384.

6. Hillmen P, Cohen DR, Cocks K, et al. A randomized phase II trial of fludarabine, cyclophosphamide and mitoxantrone (FCM) with or without rituximab in previously treated chronic lymphocytic leukaemia. Br J Haematol. 2011;152:570-578.

7. Gribben JB, Hosing C, Maloney DG. Stem cell transplantation for indolent lymphoma and chronic lymphocytic leukemia. Biol Blood Marrow Transplant. 2011;17(1 Suppl):S63-S70.

8. Pekova S, Mazal O, Cmejla R, et al. A comprehensive study of TP53 mutations in chronic lymphocytic leukemia: Analysis of 1287 diagnostic and 1148 follow-up CLL samples. Leuk Res. January 11, 2011. [Epub ahead of print].

9. Furman RR. Prognostic markers and stratification of chronic lymphocytic leukemia. Hematology Am Soc Hematol Educ Program. 2010; 77-81.

10. Molica S. Quality of life in chronic lymphocytic leukemia: A neglected issue. Leuk Lymphoma. 2005;46:1709-1714.

11. Else M, Smith AG, Cocks K, et al. Patients' experience of chronic lymphocytic leukaemia: Baseline health-related quality of life results from the LRF CLL4 trial. Br J Haematol. 2008;143:690-697.

12. Abrisqueta $P$, Pereira A, Rozman C, et al. Improving survival in patients with chronic lymphocytic leukemia (1980-2008): The Hospital Clinic of Barcelona experience. Blood. 2009;114:2044-2050.

13. Hallek M, Fischer K, Fingerle-Rowson G, et al. Addition of rituximab to fludarabine and cyclophosphamide in patients with chronic lymphocytic leukaemia: A randomised, open-label, phase 3 trial. Lancet. 2010;376: 1164-1174.

14. Robak T, Dmoszynska A, Solal-Céligny P, et al. Rituximab plus fludarabine and cyclophosphamide prolongs progression-free survival compared with fludarabine and cyclophosphamide alone in previously treated chronic lymphocytic leukemia. J Clin Oncol. 2010;28: 1749-1755.

15. Dearden C. Disease-specific complications of chronic lymphocytic leukemia. Hematology Am Soc Hematol Educ Program. 2008: $450-456$.

16. Tsopra OA, Ziros PG, Lagadinou ED, et al. Disease-related anemia in chronic lymphocytic leukemia is not due to intrinsic defects of erythroid precursors: A possible pathogenetic role for tumor necrosis factor-alpha. Acta Haematol. 2009;121:187-195.

17. Spivak JL, Gascon P, Ludwig H. Anemia in management of oncology and hematology. Oncologist. 2009;14 Suppl 1:43-56.

18. Letilovic T, Vrhovac R, Verstovsek S, Jaksic B, Ferrajoli A. Role of angiogenesis in chronic lymphocytic leukemia. Cancer. 2006;107: 925-934.

19. Molica S, Cutrona G, Vitelli G, et al. Markers of increased angiogenesis and their correlation with biological parameters identifying high-risk patients in early B-cell chronic lymphocytic leukemia. Leuk Res. 2007;31:1575-1578.

20. Schrjivers D, Highley M, DeBruyn E, et al. Role of red blood cell in pharmacokinetics of chemotherapeutic agents. Anticancer Drugs. 1999; 10:147-153
21. Benson K, Balducci L, Aapro M. Anemia and cancer. In: Balducci L, Ershler WB, Bennett JM, editors. Anemia in the Elderly. New York, NY: Springer; 2007.

22. Rai KR, Sawitsky A, Cronkite EP, Chanana AD, Levy RN, Pasternack BS. Clinical staging of chronic lymphocytic leukemia. Blood. 1975;46:219-234.

23. Binet JL, Auquier A, Dighiero G, et al. A new prognostic classification of chronic lymphocytic leukemia derived from a multivariate survival analysis. Cancer. 1981;48:198-206.

24. Moreno C, Hodgson K, Ferrer G, et al. Autoimmune cytopenia in chronic lymphocytic leukemia: Prevalence, clinical associations and prognostic significance. Blood. 2010;116:4771-4776.

25. Rizzo JD, Brouwers M, Hurley P, et al. American Society of Hematology/American Society of Clinical Oncology clinical practice guideline. Update on the use of epoetin and darbepoetin in adult patients with cancer. J Clin Oncol. 2010;28:4996-5010.

26. Rose E, Rai K, Revicki D, Brown R, Reblando J. Clinical and health status assessments in anemic chronic lymphocytic leukemia (CLL) patients treated with epoetin alfa (EPO). Blood. 1994;84 Suppl:Abstr 526a.

27. Siakantaris MP, Angelopoulou MK, Vassilakopoulos TP, Dimopoulou MN, Kontopidou FN, Pangalis GA. Correction of disease-related anemia of B-chronic lymphoproliferative disorders by recombinant human erythropoietin: Maintenance is necessary to sustain response. Leuk Lymphoma. 2000;40:141-147.

28. Österborg A, Brandberg Y, Molostova V, et al. Randomized, doubleblind, placebo-controlled trial of recombinant human erythropoietin, epoetin beta, in hematologic malignancies. J Clin Oncol. 2002;20: 2486-2494.

29. Pangalis GA, Siakantaris MP, Angelopoulou MK, et al. Downstaging Rai stage III B-chronic lymphocytic leukemia patients with the administration of recombinant human erythropoietin. Haematologica. 2002;87:500-506

30. Henke M, Laszig R, Rube C, et al. Erythropoietin to treat head and neck cancer patients with anaemia undergoing radiotherapy: Randomized, double-blind, placebo controlled trial. Lancet. 2003;362: 1255-1260.

31. Leyland-Jones B, Semiglazov V, Pawlicki M, et al. Maintaining normal hemoglobin levels with epoetin alfa in mainly nonanemic patients with metastatic breast cancer receiving first-line chemotherapy: A survival study. J Clin Oncol. 2005;23:5960-5972.

32. Kokhaei P, Abdalla AO, Hansson L, et al. Expression of erythropoietin receptor and in vitro functional effects of epoetins in B-cell malignancies. Clin Cancer Res. 2007;13:3536-3544.

33. Aapro M, Osterwalder B, Scherhag A, Burger HU. Epoetin-beta treatment in patients with cancer chemotherapy-induced anaemia: The impact of initial haemoglobin and target haemoglobin levels on survival, tumour progression and thromboembolic events. Br J Cancer. 2009;101:1961-1971.

34. Ludwig H, Rai K, Blade J, et al. Management of disease-related anemia in patients with multiple myeloma or chronic lymphocytic leukemia: Epoetin treatment recommendations. Hemat J. 2002;3: 121-130.

35. Rizzo JD, Lichtin AE, Woolf SH, et al. Use of epoetin in patients with cancer: Evidence-based clinical practice guidelines of the American Society of Clinical Oncology and the American Society of Hematology. J Clin Oncol. 2002;20:4083-4107.

36. Rizzo JD, Somerfield MR, Hagerty KL, et al. Use of epoetin and darbepoetin in patients with cancer: 2007 American Society of Clinical Oncology/American Society of Hematology clinical practice guideline update. J Clin Oncol. 2008;26:132-149.

37. Ross SD, Allen IE, Henry DH, Seaman C, Sercus B, Goodnough LT. Clinical benefits and risks associated with epoetin and darbepoetin in patients with chemotherapy-induced anemia: A systematic review of the literature. Clin Ther. 2006;28:801-831. 
38. Timmer SA, De Boer K, Knaapen P, Götte MJ, Van Rossum AC. The potential role of erythropoietin in chronic heart failure: From the correction of anemia to improved perfusion and reduced apoptosis? J Card Fail. 2009;15:353-361.

39. Brown JR. Immunomodulators in chronic lymphocytic leukemia: Where does lenalidomide belong? Leuk Lymphoma. 2010;51:1382-1385.
40. Mauro FR, Gentile M, Foa R. Erythropoietin and chronic lymphocytic leukemia. Rev Clin Exp Hematol. 2002;Suppl 1:21-31.

\section{Publish your work in this journal}

Cancer Management and Research is an international, peer-reviewed open access journal focusing on cancer research and the optimal use of preventative and integrated treatment interventions to achieve improved outcomes, enhanced survival and quality of life for the cancer patient The journal welcomes original research, clinical \& epidemiological studies, reviews \& evaluations, guidelines, expert opinion \& commentary, case reports \& extended reports. The manuscript management system is completely online and includes a very quick and fair peerreview system, which is all easy to use. Visit http://www.dovepress.com/ testimonials.php to read real quotes from published authors.

Submit your manuscript here: http://www.dovepress.com/cancer-management-and-research-journal 